\title{
The Influence of Instrumental Line Shape Degradation on Gas Retrievals and Observation of Greenhouse Gases in Maoming, China
}

\author{
Dandan Liu ${ }^{1, *(\mathbb{D}}$, Yinbo Huang ${ }^{2}$, Zhensong Cao ${ }^{2}$, Xingji Lu ${ }^{2}$ and Xiangyuan Liu ${ }^{1}$ \\ 1 College of Electrical and Optoelectronic Engineering, West Anhui University, Luan 237012, China; \\ baobaoldd@126.com \\ 2 Key Laboratory of Atmospheric Optics, Anhui Institute of Optics and Fine Mechanics, Chinese Academy \\ of Sciences, Hefei 230031, China; ybhuang@aiofm.ac.cn (Y.H.); zscao@aiofm.ac.cn (Z.C.); \\ 1xj168@mail.ustc.edu.cn (X.L.) \\ * Correspondence: dandan86@mail.ustc.edu.cn; Tel.: +86-18860465860
}

check for

updates

Citation: Liu, D.; Huang, Y.; Cao, Z.; $\mathrm{Lu}, \mathrm{X}$.; Liu, X. The Influence of Instrumental Line Shape Degradation on Gas Retrievals and Observation of Greenhouse Gases in Maoming, China. Atmosphere 2021, 12, 863. https://doi.org/10.3390/atmos 12070863

Academic Editors: Bo Sun and Helene R. Langehaug

Received: 18 May 2021

Accepted: 30 June 2021

Published: 2 July 2021

Publisher's Note: MDPI stays neutral with regard to jurisdictional claims in published maps and institutional affiliations.

Copyright: (c) 2021 by the authors. Licensee MDPI, Basel, Switzerland. This article is an open access article distributed under the terms and conditions of the Creative Commons Attribution (CC BY) license (https:// creativecommons.org/licenses/by/ $4.0 /$ )

\begin{abstract}
The instrument line shape (ILS), as a very important parameter, has a significant influence on the inversion of trace gas concentration. Different levels of ILS degradation for $\mathrm{H}_{2} \mathrm{O}, \mathrm{CO}_{2}, \mathrm{CH}_{4}$, and $\mathrm{CO}$ gases were investigated, and the influence of ILS on the inversion of column-averaged dry air mole fractions (DMFs) was assessed. Our results indicate that the averages of $\mathrm{XH}_{2} \mathrm{O}, \mathrm{XCH}_{4}$, and $\mathrm{XCO}$ with modulation efficiency (ME) amplitude values have a positive correlation, the correlation coefficients are $0.9925,0.9968$, and 0.9981 respectively, whereas the relationship between the average of $\mathrm{XCO}_{2}$ and ME is a negative correlation with 0.986 correlation coefficient. For a typical ILS degradation, a decrease of $5 \%$ in the modulation efficiency amplitude value results in the average of $\mathrm{XCO}_{2}$ changing by $0.744 \%, \mathrm{XCH}_{4}$ and $\mathrm{XH}_{2} \mathrm{O}$ are less sensitive species, with average values of $-0.206 \%$ and $-0.464 \%$, whereas XCO shows the strongest intraday variability with an average value of $-0.238 \%$. However, with a decrease of $2 \%$ in the phase error (PE) value, the average of $\mathrm{XCO}$ changed by $-0.150 \%, \mathrm{XCO}_{2}$ and $\mathrm{XH}_{2} \mathrm{O}$ almost coincided with the same average value of $-0.141 \%$, whereas $\mathrm{XCH}_{4}$ was the least sensitive species with an average value of $-0.133 \%$. At the same time, we measured the ILS for EM27/SUN spectrometers-the mean values of modulation efficiency amplitudes and phase errors were 0.9611 and 0.00593 . Compared with standard values, the modulation efficiency amplitudes and the phase error deviations were $2.450 \%$ and $0.433 \%$. During the observation period, the daily average of $\mathrm{XCO}_{2}$ ranged from 415.09 to $421.78 \mathrm{ppm}$. $\mathrm{XCH}_{4}$ ranged from 1.96 to $2.02 \mathrm{ppm}$ with a mean of $1.982 \mathrm{ppm}$, and the daily average of XCO ranged from 0.118 to $0.157 \mathrm{ppm}$ with a mean of $0.137 \mathrm{ppm}$. For the relationship between $\mathrm{XCO}_{2}$ and $\mathrm{XCH}_{4}$, the linear regression line shows a good correlation with the correlation coefficient $R^{2} \geq 0.5$. Especially, for the correlation coefficient $\mathrm{R}^{2}=0.82$ on 8 October, our studies found a weak correlation in the variation of $\mathrm{CO}_{2}$ and $\mathrm{CO}$ during the observations. The correlation coefficient $\mathrm{R}^{2} \geq 0.5$ was only found on 30 September and 3 October. The trajectories dram at a height of $10 \mathrm{~km}$ give a hint of trace gas transport from the bay of western India, Bengal, and the Arabian Sea, whereas for the trajectories dram boundary layer height, trace gases were transported from southwest and east of China. These results provide a theoretical basis to understand the time and space distribution and the changes of greenhouse gas in the atmosphere as well as providing a theoretical basis for calculations of atmospheric radiation transmission.
\end{abstract}

Keywords: Fourier transform infrared spectroscopy; greenhouse gases; ILS; DMFs; HYSPLIT

\section{Introduction}

The continuing increase of atmospheric greenhouse gas is the main driver of global warming, particularly carbon dioxide $\left(\mathrm{CO}_{2}\right)$, methane $\left(\mathrm{CH}_{4}\right)$, and carbon monoxide $(\mathrm{CO})$. In recent years, many countries have put great efforts into the observation of concentrations 
of greenhouse gases, including total column concentration, column-averaged dry air mole fractions, and flux of greenhouse gases with global coverage. For example, the Greenhouse Gases Observing Satellite (GOSAT) launched by Japan and the Orbiting Carbon Obserbvatory-2 (OCO-2) satellite launched by the USA are tasked with long-term observations of global greenhouse gas concentrations [1-4]. The data derived from satelliteborne sensing have provided useful information but results still need to be validated. The ground-based Fourier transform spectrometer can accurately measure greenhouse gas concentrations by recording direct solar spectra for the validation of satellite-borne results. There are two well-known international networks based on ground-based solar FTIR instruments: the Total Carbon Column Observing Network and the Network for the Detection of Atmospheric Composition Change [5,6]. Both TCCON and NDACC networks have more than 20 sites around the word, and are dedicated to retrieval of total column concentration of $\mathrm{CO}_{2}, \mathrm{CH}_{4}, \mathrm{CO}$, and other gases by ground-based high resolution Fourier transform infrared (FTIR) spectrometers (the type 125HR from Bruker). For example, Messerschmidit et al. (2011) claimed that the accuracy and precision of a column-averaged dry air mole fraction of $\mathrm{CO}_{2}$ was better than $0.25 \%$ [7]. However, due to the type 125HR spectrometers applied for two networks not being portable, it is difficult for observation of sources and sinks on a regional scale. A portable low resolution FTIR spectrometer EM27/SUN has the advantages of lightweight, excellent stability, and lowcost use for the observation of greenhouse gases by recording direct solar spectra. The long-term performance of the EM27/SUN spectrometer with respect to a reference high resolution instrument was investigated. Namely, Gisi et al. (2012) found that the total column $\mathrm{XCO}_{2}$ by EM27/SUN using solar absorption spectroscopy was in agreement with TCCON results with $(0.12 \pm 0.08) \%$ being achieved [8]. Hase et al. (2015), and Frey et al. (2015) combined several EM27/SUN spectrometers to estimate urban carbon dioxide and $\mathrm{CH}_{4}$ emissions [9,10].

With the high precision requirements of remote sensing applications, atmospheric radiation transfer calculation, instrument model, and inversion algorithm are the main factors restricting atmospheric trace gas inversion. In the instrument model, the instrument line shape (ILS) is the most important parameter, which determines the degree of modulation of the instrument on the incident radiation, that is, the spectral resolution of the instrument and the spectral line energy distribution. The ILS can be divided into two parts. The first part describes the modulation loss caused by the inherent self-apodization of the instrument. It can be used to calculate the optical thickness OPD of the spectrometer and the field of view FOV. The second part is caused by the uncalibrated and optical phase difference of the instrument, characterized by modulation efficiency (ME) amplitude and phase error (PE). The modulation efficiency amplitude characterizes the width of ILS, and the phase error quantifies the degree of ILS symmetry. A standard procedure to derive the ILS of the TCCON and NADCC spectrometer are gas cell measurements, using a low-pressure calibration gas cell to diagnose a misalignment of the spectrometer. For example, the ILS of the TCCON spectrometer is a HCL gas cell. In contrast, a successful alignment scheme for low-resolution spectrometers was proposed, the ILS of a EM27/SUN spectrometer by measuring the $\mathrm{H}_{2} \mathrm{O}$ spectrum in laboratory air to calibrate the ILS of the instrument. As light source a collimated standard $50 \mathrm{~W}$ halogen light bulb was used. Recently, researchers studied the effect of the ILS on gas inversion. Such as, the ILS modulation efficiency of the EM27/SUN spectrometer before and after the campaign with $0.24 \%$, corresponding to a change of only $0.04 \%$ for the $\mathrm{XCO}_{2}$ [8]. An increase of $1 \%$ in the modulation efficiency results in an $\mathrm{XCO}_{2}$ increase of $0.15 \%$, whereas $\mathrm{XCH}_{4}$ increases $0.1 \%$ [8,11]. In the study of Frey 2018, the modulation efficiency at maximum optical path difference ranges between 0.9835 and 0.9896 , with a mean value of 0.9862 and a standard deviation of 0.0015 . The phase error was close to zero for the whole time series with a mean value of $0.0019 \pm 0.0018$ by studying ILS of thirty EM27/SUN.

In the first part of this study, we quantitatively calculated the impact of ILS degradation on $\mathrm{XH}_{2} \mathrm{O}, \mathrm{XCO}_{2}, \mathrm{XCH}_{4}$, and $\mathrm{XCO}$ and analyzed the average gas concentration changes 
with modulation efficiency amplitude and phase error. We performed lab-air observations of water gas signatures for the determination of instrumental line shape characteristics and obtained the values of ME and PE. Moreover, the change trend of greenhouse gas concentration in the Maoming area was analyzed, while at the same time we analyzed the correlation between $\mathrm{XCH}_{4}, \mathrm{XCO}$, and $\mathrm{XCO}_{2}$.

\section{Measurement Sit and Instruments}

Measurements of the trace gases were made using the EM27/SUN spectrometer for $\mathrm{XH}_{2} \mathrm{O}, \mathrm{XCO}_{2}, \mathrm{XCH}_{4}$, and $\mathrm{XCO}$. The instruments were located at Bohe Marine Meteorological Observatory $\left(21.453^{\circ} \mathrm{N}, 111.315^{\circ} \mathrm{E}, 0.02 \mathrm{~km}\right.$ above sea level), adjacent to the South China Sea, located in the south Binhai New area of Maoming city (Figure 1 left). The coastline is very straight and has no terrain blocking, which is very conducive to the observation of various marine meteorological elements. We installed the instrument, consisting of the EM27/SUN spectrometer and solar tracker. A detailed description of the spectrometer can be found in Gisi et al. (2012), in the following we give only a short overview.
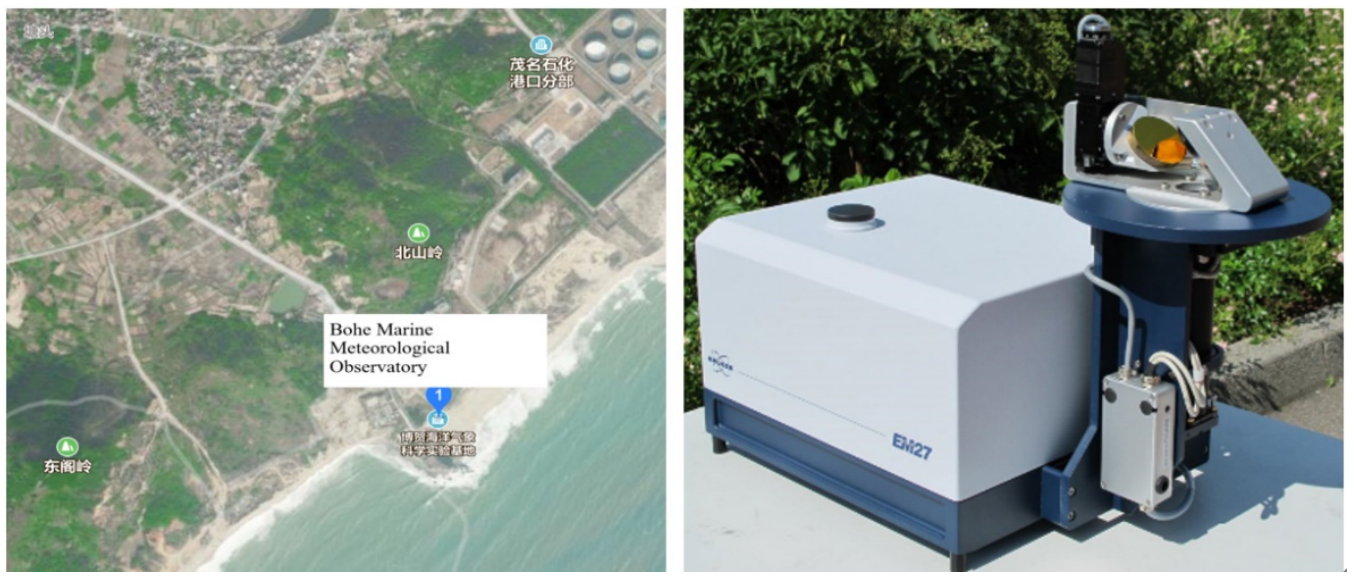

Figure 1. Observing site (Bohe Marine Meteorological Observatory, left). FTIR spectrometer (EM27/SUN, right).

To reach high stability with regard to thermal influences and vibrations, the EM27/SUN features a RockSolidTM pendulum interferometer with two cube corner mirrors and a $\mathrm{CaF}_{2}$ beam splitter. The instrument achieves $1.8 \mathrm{~cm}$ optical path difference (OPD) with a maximum spectral resolution of $0.5 \mathrm{~cm}^{-1}$, as shown in Figure 1 (right). Measurements are recorded with an InGaAs detector operated at ambient temperature. Due to spectral coverage from 5000 to $11,000 \mathrm{~cm}^{-1}$, the spectral bandwidth enables the detection of $\mathrm{O}_{2}$, $\mathrm{H}_{2} \mathrm{O}, \mathrm{CO}_{2}, \mathrm{CH}_{4}$, and $\mathrm{CO}$. The detector signal is DC coupled and thereby supports the correction of variable atmospheric transmission [12].

\section{Data Processing and Methods}

This section provides a concise and precise description of the experimental results, their interpretation, as well as the experimental conclusions that can be drawn.

Atmospheric $\mathrm{CO}_{2}, \mathrm{CH}_{4}$, and $\mathrm{CO}$ are measured with a ground-based Fourier transform spectrometer that records the near infrared spectrum. We recorded double-sided interferograms with $0.5 \mathrm{~cm}^{-1}$ resolution. With 10 scans, one measurement takes about $58 \mathrm{~s}$. In order to ensure data quality, a pre-processing is performed. To suppress the negative sidelobes, sometimes a numerical apodisation is applied. This is especially important for low resolution instruments. On the downside an apodisation decreases the spectral resolution and amplifies the correlation between measured values from different spectral positions. A good compromise between acceptable resolution, degradation, and suppressing the negative sidelobes is the Norton-Beer medium function [13]. Furthermore, a DC correction is performed. In addition, a quality filter discards interferograms with intensity 
fluctuations above $10 \%$ and intensities below $10 \%$ of the maximal modulation amplitude. To ensure high-precision greenhouse gas concentration, not only the altitude, latitude, and longitude, a priori temperature, humidity, pressure, and other parameters need to be considered, but also the real-time meteorological parameters of the site, such as surface temperature, surface pressure, and the instrumental characteristics of the measurement device (ILS), etc.

Precise knowledge of instrumental line shape (ILS) is of utmost importance to gain correct information from measurement signals. Instrumental line shape is the Fourier transform of the weighting applied to the interferogram. It consists of two parts and affects the accuracy of the final inversion results. Due to inherent self-apodization of the spectrometer, which is present also in an ideal instrument, one part describes the modulation loss. This contribution can easily be calculated utilizing the OPD and FOV of the spectrometer. The other part of the ILS results from misalignments and optical aberrations of the spectrometer and can be described by a modulation efficiency amplitude (ME) and a phase error (PE) as a function of the OPD. The theoretical ideal ILS, is a convolution of sinc and rectangular functions, representing the finite length of the interferogram and the finite circular field of view of the spectrometer [14], defined as:

$$
\begin{gathered}
\operatorname{Sinc}(\sigma, L)=2 L \frac{\sin (2 \pi \sigma L)}{2 \pi \sigma L} \\
\operatorname{Rect}\left(\sigma, \sigma_{0}, \theta\right)=\left\{\begin{array}{cc}
\frac{2}{\sigma_{0} \theta^{2}} & -0.5 \sigma_{0} \theta^{2} \leq \sigma \leq 0 \\
0 & \text { otherwise }
\end{array}\right. \\
\operatorname{ILS}\left(\sigma, \sigma_{0}, L, \theta\right)=\operatorname{Sinc}(\sigma, L) \times \operatorname{Rect}\left(\sigma, \sigma_{0}, \theta\right)
\end{gathered}
$$

Here, $\sigma$ is the wavenumber, $\sigma_{0}$ is the central wavenumber, $L$ is the optical path difference, and $\theta$ is the angular radius of the circular internal FOV of the spectrometer. The ILS of a real spectrometer is equivalent to complex modulation efficiency in the interferogram, many problems lead to smooth variation of the complex modulation efficiency as for example, misalignments and optical aberrations of the spectrometer. The phase corrected interferogram generated by a spectral line is of the form [15]:

$$
\operatorname{IFG}(x) \sim \operatorname{Mod} \_a m p(x) \cdot \cos \left(2 \pi \sigma-\operatorname{Mod} \_p h a s(x)\right)
$$

where $\operatorname{IFG}(x)$ is the interferogram, $\operatorname{Mod} \_\operatorname{amp}(x)$ is the modulation efficiency amplitude $(\mathrm{ME})$, and Mod_phas $(x)$ is the phase error (PE). The spectral resolution is defined as:

$$
\Delta \mathrm{v}=0.9 / M O P D
$$

MOPD means the maximum optical path difference.

In this work, we analyzed spectra utilizing the PROFFIT retrieval fitting algorithm [10], which is in wide use and has been validated for retrieving dry-air mole fractions (DMF) of trace gases [8,16-18]. The PROFFIT is a non-linear least-squares fitting algorithm. The atmospheric forward model is used to calculate synthetic spectra. We fitted the atmospheric spectra by scaling of a priori trace gas profiles with low resolution of the EM27/SUN as well as a priori vertical profiles for temperature, pressure, and water gas from the National Centers for Environmental Prediction (NCEP). Then an inverse method compares the synthetic spectra with the measured spectra. Typically, an inversion calculation starts with a forward model $\vec{F}(\vec{x})$, includes the instrumental characteristics of the measurement device and underlying physics which relates the measured quantities and the target variable. The approximation of the physics of the measurement process:

$$
\vec{y}=\vec{F}(\vec{x})+\vec{\varepsilon}_{y}
$$


Here, $\vec{y}$ represents the measurement with the corresponding measurement error $\vec{\varepsilon}_{y}, \vec{x}$ is state vector, include pressure, temperature, or the volume mixing ratio. The assumption of discrete values for these parameters, the linearization of the forward model:

$$
\begin{aligned}
\vec{F}(\vec{x}) & =\vec{F}\left(\vec{x}_{0}\right)+\frac{\partial \vec{F}}{\partial \vec{x}}\left(\vec{x}-\vec{x}_{0}\right)+\vec{\varepsilon}_{y} \\
& =\vec{F}\left(\vec{x}_{0}\right)+\mathbf{K}\left(\vec{x}-\vec{x}_{0}\right)+\vec{\varepsilon}_{y}
\end{aligned}
$$

Here, $\vec{x}_{0}$ is the reference state, $\mathbf{K}$ is the Jacobian matrix. The fitting residual is defined as follows:

$$
|\Delta y|^{2} S_{y}^{-1}=\left|y_{\text {meas }}-y\right|^{2} S_{y}^{-1}=\left(y_{\text {meas }}-y\right)^{T} S_{y}^{-1}\left(y_{\text {meas }}-y\right)
$$

where $y_{\text {meas }}$ is the measured spectrum, $y$ is the synthetic spectrum, $S_{y}^{-1}$ is the covariance matrix of inversion state parameters. The volume mixing ratio of $\mathrm{O}_{2}$ in the atmospheric altitude range up to $100 \mathrm{~km}$ is nearly constant at approximately 0.2095 . The calculation of the ratio of the target gas and the column amount of $\mathrm{O}_{2}$ retrieved from the same spectrum to remove the effects of surface pressure variation, the column-averaged dry air mole fraction (DMF) is defined as (9), using the column abundance of $\mathrm{O}_{2}$ as a reference to reduce the systematic errors:

$$
X_{\text {gas }}=0.2095 \times \frac{\text { Column }_{\text {gas }}}{\text { Column }_{\mathrm{O}_{2}}}
$$

where column gas and column $\mathrm{O}_{2}$ are the column abundance of the retrieval gas and $\mathrm{O}_{2}$ respectively. Details of the retrieval method are given in Inverse Methods for Atmospheric Sounding: Theory and Practice [18]. The spectra windows for retrieval of the columnaveraged dry air mole fraction (DMF) $\mathrm{CO}_{2}, \mathrm{CH}_{4}, \mathrm{CO}$, and $\mathrm{O}_{2}$ are listed in Table 1. To make the measurements comparable to WMO scale, in post processing in our work, the calibration factors applied for $\mathrm{XCO}_{2}, \mathrm{XCH}_{4}$, and XCO were $0.9869,0.9898$, and 0.925 , respectively [11]. Figure 2 shows a typical measured atmospheric spectrum, the mode spectrum, and residuals.

Table 1. Spectral windows for retrieval of the column of $\mathrm{CO}_{2}, \mathrm{CH}_{4}$, and $\mathrm{CO}$.

\begin{tabular}{ccc}
\hline Gas & Spectral Windows $\left[\mathrm{cm}^{-1}\right]$ & Interfering Molecule \\
\hline $\mathrm{CO}_{2}$ & $6173.0-6390.0$ & $\mathrm{H}_{2} \mathrm{O}, \mathrm{HDO}, \mathrm{CH}_{4}$ \\
$\mathrm{CH}_{4}$ & $5897.0-6145.0$ & $\mathrm{H}_{2} \mathrm{O}$ \\
$\mathrm{CO}$ & $4208.7-4318.8$ & $\mathrm{CH}_{4}, \mathrm{H}_{2} \mathrm{O}, \mathrm{HDO}$ \\
$\mathrm{O}_{2}$ & $7765.0-8005.0$ & $\mathrm{H}_{2} \mathrm{O}, \mathrm{HF}, \mathrm{CO}_{2}$ \\
\hline
\end{tabular}

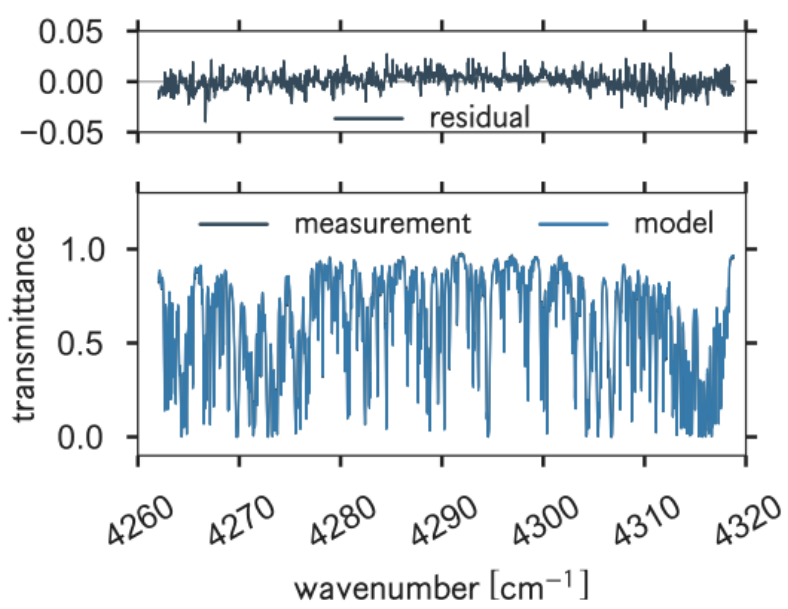

Figure 2. Typical measured atmospheric spectrum, mode spectrum, and residuals. 


\section{Results Measurements and Discussion}

The ME amplitude is connected to the width of the ILS, while the PE quantifies the degree of ILS asymmetry. The modulation efficiency amplitude (ME) is unity and the phase error (PE) is zero with an ideal ILS. However, if the spectrometer is not calibrated, the ME amplitude and PE would deviate from unity and zero. These parameters have to be calculated from laboratory measurement.

\subsection{Influence of Instrumental Line Shape on Greenhouse Gas Inversion}

In order to quantitatively analyze the impact of ILS on inversion, we analyzed the concentration changes of $\mathrm{XH}_{2} \mathrm{O}, \mathrm{XCO}_{2}, \mathrm{XCH}_{4}$ and $\mathrm{XCO}$, when the $\mathrm{ME}$ deviate from $\pm 5 \%$, $\pm 10 \%, \pm 15 \%, \pm 20 \%$ compared to the ideal value unity, and the PE deviate from $\pm 2 \%$, $\pm 4 \%$ o $\pm 6 \%$ o $\pm 8 \%$ o $\pm 10 \%$ o compared to the ideal value zero. We took the retrievals with an ideal ILS as the reference. The difference is defined as:

$$
D \%=\frac{X-X_{r e f}}{X_{r e f}} \times 100
$$

Taking the standard instrument as reference, the influence of the modulation efficiency amplitudes and phase errors on greenhouse gas inversion are shown in Figure 3. In general, the mean of $\mathrm{XH}_{2} \mathrm{O}, \mathrm{XCH}_{4}$, and $\mathrm{XCO}$ with $\mathrm{ME}$ values has a positive correlation. The correlation coefficients are $0.9925,0.9968$, and 0.9981 respectively. However, the relationship between the mean of $\mathrm{XCO}_{2}$ and $\mathrm{ME}$ is the opposite, the mean of $\mathrm{XCO}_{2}$ decreases as the ME loss increases. It has a negative correlation with $\mathrm{ME}$ loss value, the correlation coefficient is 0.986 . This is opposed to prior studies reporting an increase of $\mathrm{XCO}_{2}$ and decrease of $\mathrm{XCH}_{4}$ for an increase of the modulation efficiency [19]. The reason may be that the total amount of the gas column depends on the airmass while the interference molecules in the inversion window of each gas molecule are different. This is in agreement with the findings from Frey, $\mathrm{M}$ dissertation (2018), who reported that $\mathrm{XCO}_{2}$ decreases with increasing ILS, whereas $\mathrm{XCH}_{4}$ increases [11]. The $\mathrm{Xgas}\left(\mathrm{XH}_{2} \mathrm{O}, \mathrm{XCO}_{2}, \mathrm{XCH}_{4}\right.$ and $\left.\mathrm{XCO}\right) / \mathrm{ME}$ loss slopes are $271.3,-59.33,0.192$, and 0.0069 . The time series of relative difference of these species in terms of the total column are displayed in Figure 3c. A decrease of 5\% in the ME value results in the highest amount of $\mathrm{XCO}_{2}$ with an average value of $0.744 \%$. While $\mathrm{XCH}_{4}$ and $\mathrm{XH}_{2} \mathrm{O}$ are the less sensitive species, with average values of $-0.206 \%$ and $-0.464 \%$. Among all these species, $\mathrm{XCO}$ shows the strongest intraday variability with an average value of $-0.238 \%$, ranging from $-0.088 \%$ to $-0.831 \%$. The absorption of CO with the selected spectral window is much weaker than the other gases because of the superimposition from the nearby strong interfering lines of $\mathrm{CH}_{4}$ and $\mathrm{H}_{2} \mathrm{O}$.

The means of $\mathrm{XH}_{2} \mathrm{O}, \mathrm{XCO}_{2}, \mathrm{XCH}_{4}$, and $\mathrm{XCO}$ with different PE loss have a similar tendency, a negative correlation with $\mathrm{PE}$ loss (Figure 3 left). The correlation coefficients are higher than 0.999. The $\mathrm{Xgas}\left(\mathrm{XH}_{2} \mathrm{O}, \mathrm{XCO}_{2}, \mathrm{XCH}_{4}\right.$ and $\left.\mathrm{XCO}\right) / \mathrm{PE}$ loss slopes are -4451.08 , $-295.22,-1.35$, and -0.107 . The time series of the relative difference of these species in terms of total column shows a similar intraday variability (Figure $4 \mathrm{~d}$ ). The highest XCO has an average value of $-0.150 \%$ with a decrease of $2 \%$ in the PE value, while $\mathrm{XCO}_{2}$ and $\mathrm{XH}_{2} \mathrm{O}$ almost coincide with a same average value of $-0.141 \%$. Among all these species, $\mathrm{XCH}_{4}$ are the least sensitive species with an average value of $-0.133 \%$. Figure $4 \mathrm{a}$, b shows $\Delta \mathrm{XH}_{2} \mathrm{O}, \Delta \mathrm{XCO}_{2}, \Delta \mathrm{XCH}_{4}$, and $\triangle \mathrm{XCO}$ with $\mathrm{ME}$ and $\mathrm{PE}$ increasing or decreasing by the same value. The values of $\triangle X \mathrm{XO}_{2}$ are different when $\mathrm{ME}$ increases and decreases by the same value. Similarly, the values of $\Delta \mathrm{XCH}_{4}$ are different when $\mathrm{ME}$ increases and decreases by the same value. The reason for the asymmetry may be that the interference molecules in the retrieval band of each gas molecule are different, and the modulation degree of the instrument on the interferogram is also different, while $\Delta \mathrm{XH}_{2} \mathrm{O}$ and $\Delta \mathrm{XCO}$ are little different when ME increases and decreases by the same value. However, the values of $\Delta \mathrm{XH}_{2} \mathrm{O}, \Delta \mathrm{XCO}_{2}, \Delta \mathrm{XCH}_{4}$, and $\triangle \mathrm{XCO}$ are almost the same when PE increases and decreases by the same value. 

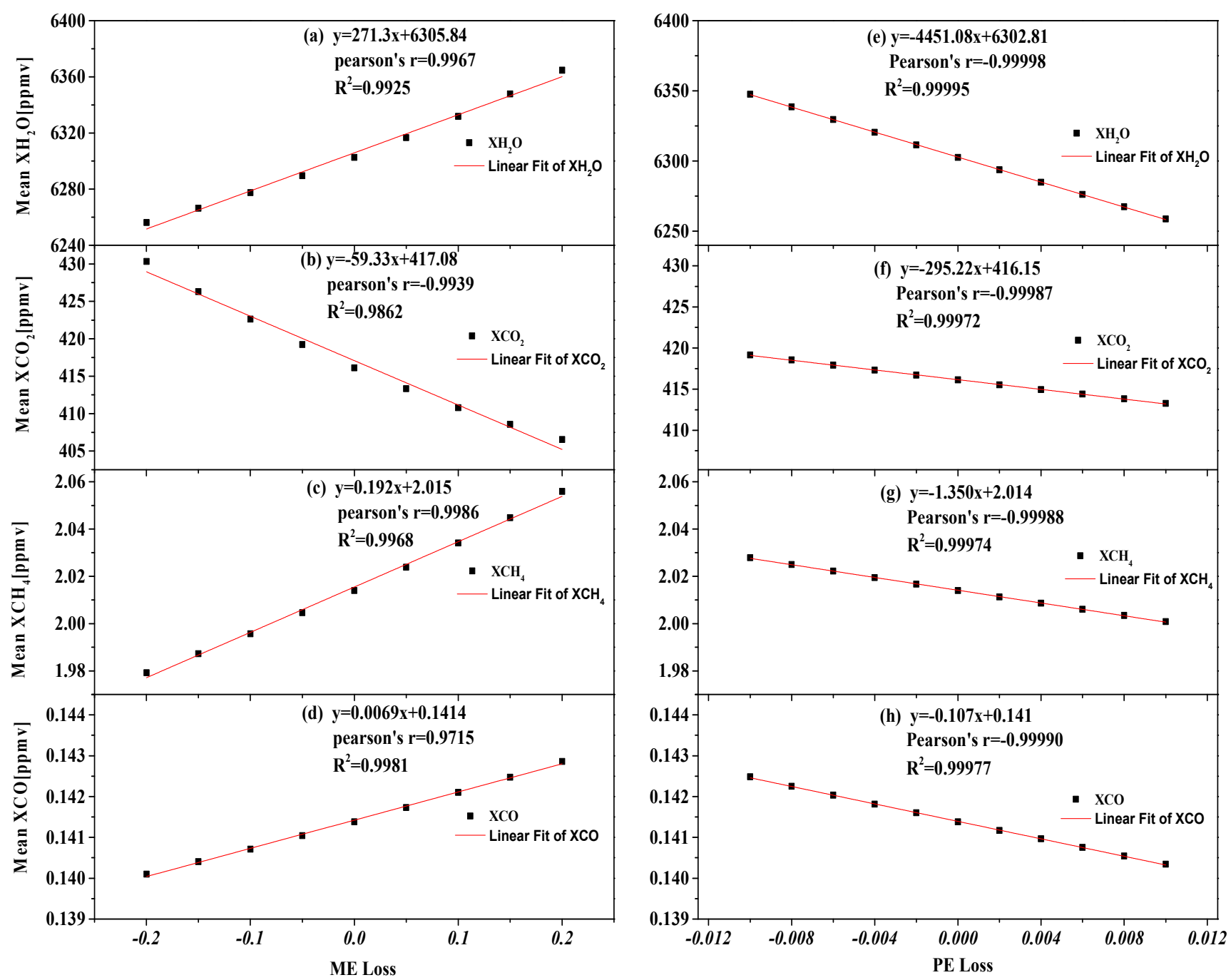

Figure 3. Influence of the modulation efficiency amplitudes and phase errors on $\mathrm{XH}_{2} \mathrm{O}, \mathrm{XCO}_{2}, \mathrm{XCH}_{4}$, and $\mathrm{XCO}$ with the reference standard instrument.

Table 2 shows the difference of $\mathrm{XH}_{2} \mathrm{O}, \mathrm{XCO}_{2}, \mathrm{XCH}_{4}$, and $\mathrm{XCO}$ with $\pm 1 \%$ in modulation efficiency and \pm 0.01 in phase error. For a typical ILS degradation of $1 \%$ in modulation efficiency, the column-averaged dry air mole fraction of $\mathrm{H}_{2} \mathrm{O}, \mathrm{CO}_{2}, \mathrm{CH}_{4}$, and $\mathrm{CO}$ changed by $0.0492,0.1151,0.1042,0.0523 \%$, respectively, while an increase of 0.01 in phase error leads to a decrease of $0.697 \%$ on $\mathrm{XH}_{2} \mathrm{O}, 0.689 \%$ on $\mathrm{XCO}_{2}, 0.652 \%$ on $\mathrm{XCH}_{4}$, and $0.737 \%$ on $\mathrm{XCO}$.

Table 2. Difference of $\mathrm{XH}_{2} \mathrm{O}, \mathrm{XCO}_{2}, \mathrm{XCH}_{4}$, and $\mathrm{XCO}$ with $\pm 1 \%$ in modulation efficiency and \pm 0.01 in phase error.

\begin{tabular}{ccccc}
\hline & $\boldsymbol{\Delta} \mathbf{X} \mathbf{H}_{\mathbf{2}} \mathbf{O}$ & $\mathbf{\Delta} \mathbf{X C \mathbf { O } _ { 2 }}$ & $\mathbf{\Delta} \mathbf{X C \mathbf { H } _ { 4 }}$ & $\Delta \mathbf{X C O}$ \\
\hline$\Delta \mathrm{ME}=1 \%$ & $0.0492 \%$ & $0.1151 \%$ & $0.1042 \%$ & $0.0523 \%$ \\
$\Delta \mathrm{ME}=-1 \%$ & $0.0368 \%$ & $0.1707 \%$ & $0.0863 \%$ & $0.0452 \%$ \\
$\Delta \mathrm{PE}=0.01$ & $0.697 \%$ & $0.689 \%$ & $0.652 \%$ & $0.737 \%$ \\
$\Delta \mathrm{PE}=-0.01$ & $0.715 \%$ & $0.729 \%$ & $0.689 \%$ & $0.775 \%$ \\
\hline
\end{tabular}



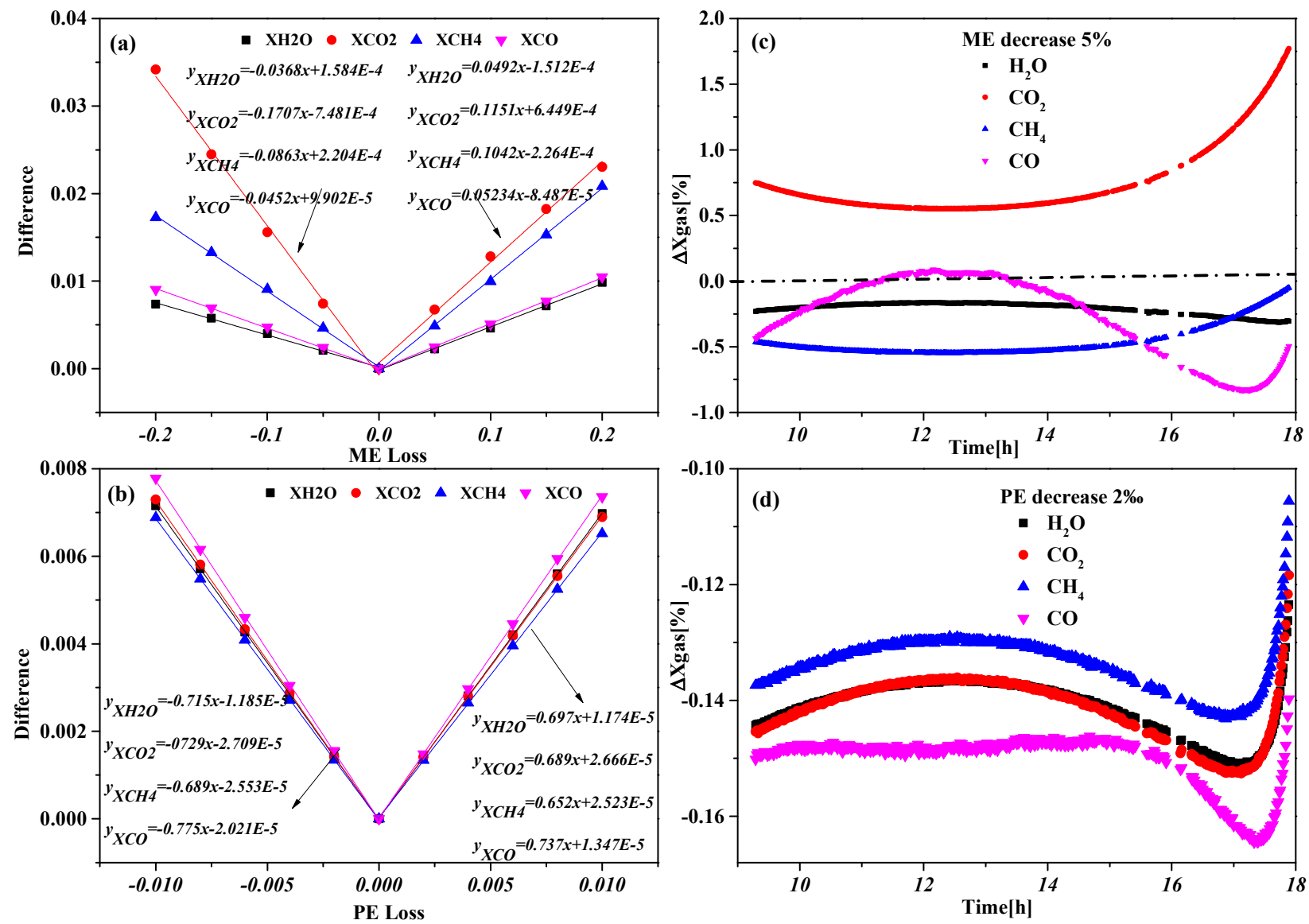

Figure 4. The e difference of $\mathrm{XH}_{2} \mathrm{O}, \mathrm{XCO}_{2}, \mathrm{XCH}_{4}$, and $\mathrm{XCO}$ with ME loss (a) and PE loss (b) with standard instrument, time series of relative difference of $\mathrm{XH}_{2} \mathrm{O}, \mathrm{XCO}_{2}, \mathrm{XCH}_{4}$, and $\mathrm{XCO}$ due to a $5 \%$ decrease of the ME values (c) and $2 \%$ rad $\mathrm{PE}$ values $(\mathbf{d})$.

\subsection{Instrumental Line Shape Monitoring}

For the EM27/SUN spectrometer, the standard procedure to derive the ILS are laboratory measurements. Several meters of lab air measurements using a collimated standard $50 \mathrm{~W}$ halogen light bulb as source (Figure 5 left) and a stabilized digital laboratory DC power $(11 \mathrm{~V})$ supply were used and the water vapor lines were evaluated in the spectral region between 7000 and $7400 \mathrm{~cm}^{-1}$. As the water column inside the spectrometer could not be neglected, the instrument was vented. The ILS retrievals are performed using LINFIT 14.5 [15]. As the ILS characteristics were close to nominal, we used the two parameters ILS model.

Due to the heat of the lamp affecting a non-negligible section of the open path, the distance between instrument and lamp should not be chosen as too small. Furthermore, the image of the lamp on the field stop is evenly illuminated and exceeds the diameter of the field stop. The resulting ILS values are presented in Tables 3 and 4 , the modulation efficiency (ME) amplitudes and phase errors (PE) are shown in Figure 5 (right). Due to the venting, the mixing ratio of $\mathrm{H}_{2} \mathrm{O}$ inside the spectrometer is the same as outside, thus the plan of the simple analysis assumes a uniform path between lamp and detector. The modulation efficiency (ME) amplitudes and phase errors are relatively close at distances of 401, 519, and $605 \mathrm{~cm}$. The mean value of the modulation efficiency (ME) amplitudes and phase errors (PE) are 0.9611and 0.00593. Compared with standard values $(\mathrm{ME}=0.9855, \mathrm{PE}=0.0016)$, the modulation efficiency (ME) amplitude and the phase error (PE) deviations are $2.450 \%$ and $0.433 \%$. The ILS results show the alignment and stability of the instrument over the whole period. For the trace gas retrieval, we used the mean value of the measurement. 

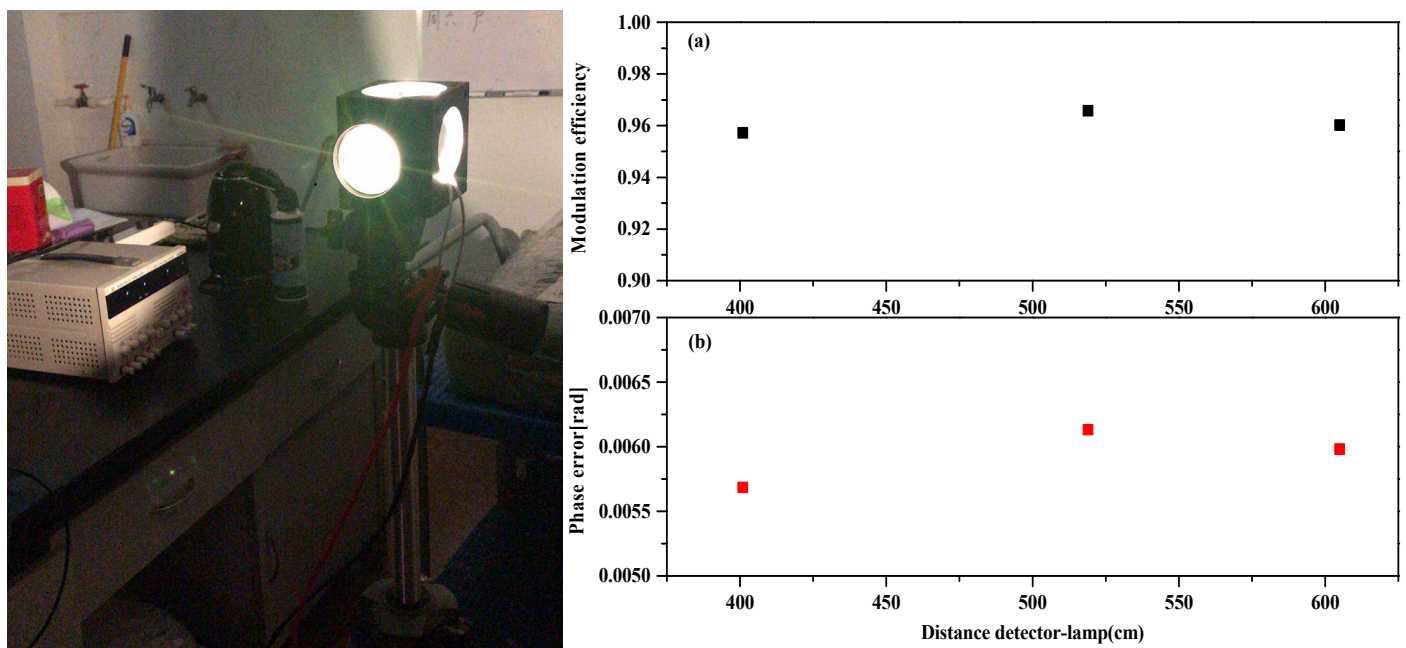

Figure 5. Light source system (Left), ME amplitudes (a) and phase errors (b) retrieved from measurements (right).

Table 3. ME amplitudes and phase errors (12 September 2018).

\begin{tabular}{ccc}
\hline Distance/cm & ME & PE \\
\hline 401 & 0.9572 & 0.00569 \\
519 & 0.9658 & 0.00613 \\
605 & 0.9602 & 0.00598 \\
mean & 0.9611 & 0.00593 \\
Standard deviation & 0.00437 & $2.23681 \times 10^{-4}$ \\
\hline
\end{tabular}

Table 4. ME amplitudes and phase errors (12 April 2019).

\begin{tabular}{ccc}
\hline Distance/cm & ME & PE \\
\hline 396 & 0.9591 & 0.00504 \\
496 & 0.9622 & 0.0048 \\
596 & 0.963 & 0.00508 \\
696 & 0.9657 & 0.00571 \\
mean & 0.9625 & 0.00516 \\
Standard deviation & 0.00272 & $3.89081 \times 10^{-4}$ \\
\hline
\end{tabular}

\subsection{Variation of $\mathrm{XCO}_{2}, \mathrm{XCH}_{4}$ and $\mathrm{XCO}$}

The direct absorption spectra were collected under clear-sky weather conditions from 30th September to 8 October 2018. The time series of the column-averaged dry air mole fraction of $\mathrm{CO}_{2}, \mathrm{CH}_{4}$ and $\mathrm{CO}$ were retrieved. Because of instrument mechanical failure or adverse weather conditions, the data were not continuous, and all datasets were calculated by Equation (9). The $\mathrm{WMO}$ calibration factors applied for $\mathrm{XCO}_{2}, \mathrm{XCH}_{4}$, and $\mathrm{XCO}$ were $0.9869,0.9898$, and 0.925 , respectively.

The diurnal variations of $\mathrm{XCO}_{2}, \mathrm{XCH}_{4}$, and $\mathrm{XCO}$ are illustrated in Figure 6. The time series of $\mathrm{XCO}_{2}, \mathrm{XCH}_{4}$, and $\mathrm{XCO}$ show a significant diurnal variation. The $\mathrm{XCO}_{2}$ and $\mathrm{XCH}_{4}$ have similar daily variation, these reached a maximum at 15:00 p.m., then dropped until sunset. The similar daily variation indicates that $\mathrm{XCO}_{2}$ and $\mathrm{XCH}_{4}$ have a good correlation, detailed analysis in Section 4.4. The daily variation of XCO slowly varies, it reaches a minimum at 16:00 p.m., then climbs until sunset. Time series of daily averages of $\mathrm{XCO}_{2}$, $\mathrm{XCH}_{4}$ and $\mathrm{XCO}$ are plotted in Figure 7. The daily average of $\mathrm{XCO}_{2}$ ranged from 415.09 to $421.78 \mathrm{ppm}$ during the campaign. $\mathrm{XCH}_{4}$ ranged from 1.96 to $2.02 \mathrm{ppm}$ with a mean of $1.982 \mathrm{ppm}$, showing higher variation than $\mathrm{XCO}_{2}$. The concentration of $\mathrm{XCH}_{4}$ shows a positive correlation with the temperature. This might be due to the warmer weather increasing the activity of methanogens [20], resulting in higher atmospheric $\mathrm{XCH}_{4}$. The daily average of $\mathrm{XCO}$ shows a similar variation tendency to $\mathrm{XCH}_{4}$. The highest $\mathrm{XCO}$ 
concentration was observed at the beginning of the measurements. The daily average of XCO ranges from 0.118 to $0.157 \mathrm{ppm}$ with a mean of $0.137 \mathrm{ppm}$.
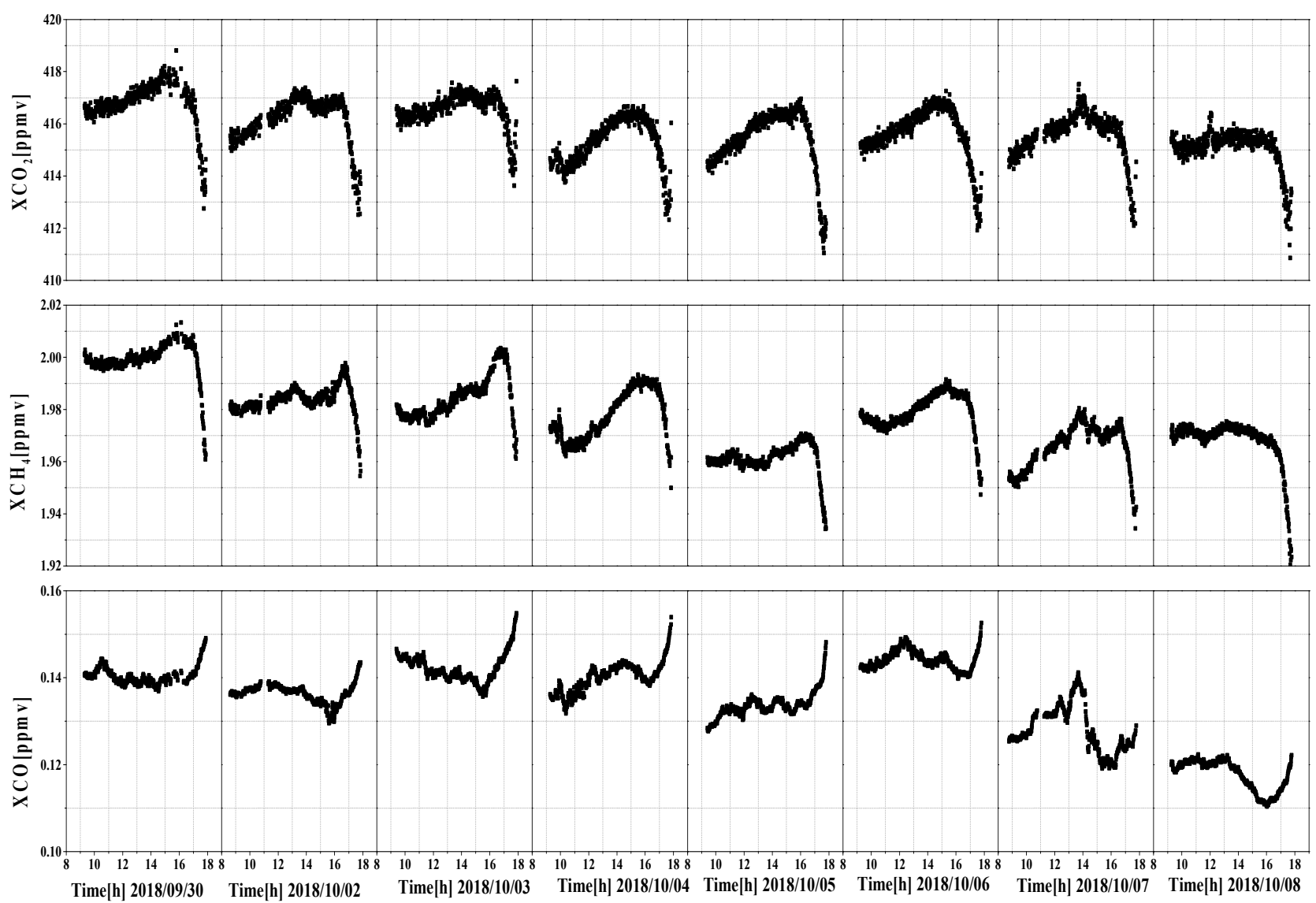

Figure 6. The four plots show the diurnal variation of $\mathrm{XCO}_{2}, \mathrm{XCH}_{4}$, and $\mathrm{XCO}$ from 30 September 2018 to 8 October 2018.

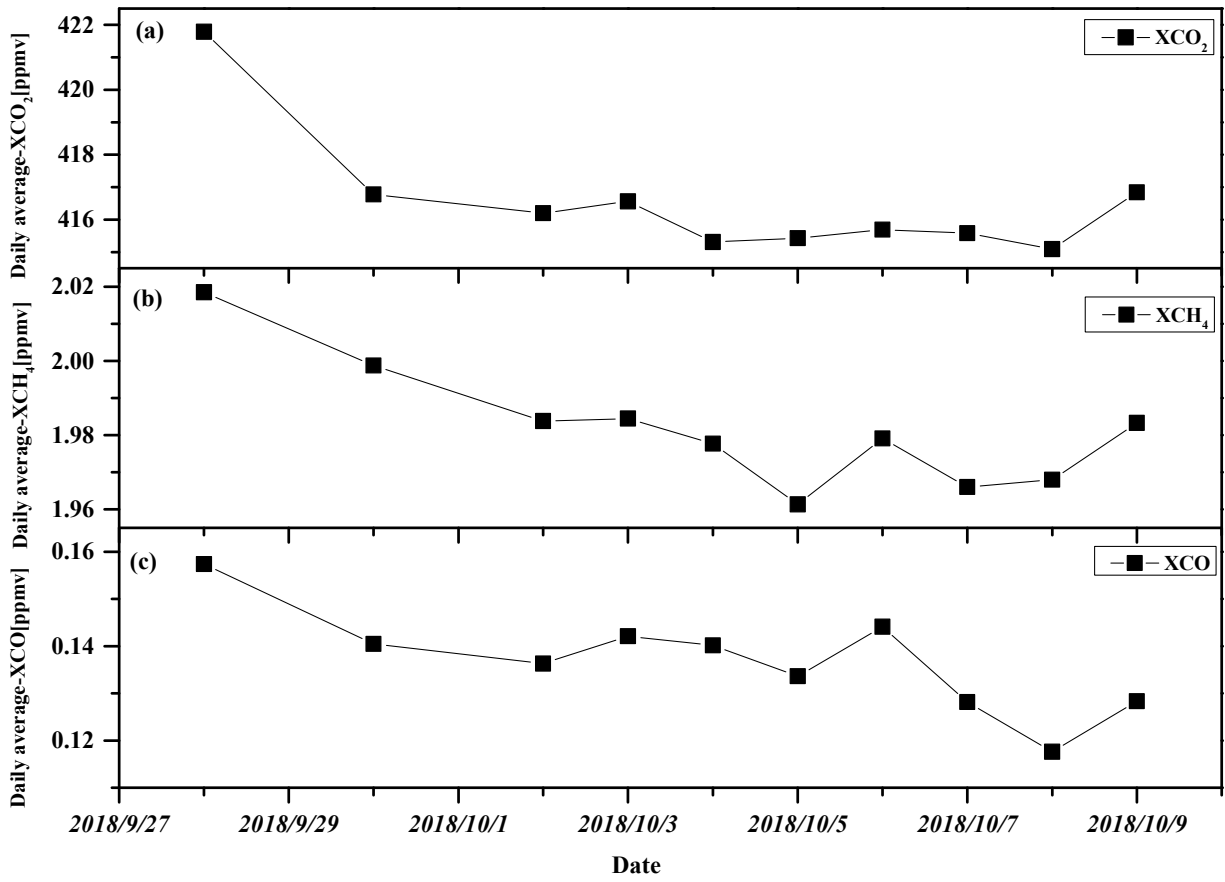

Figure 7. Time series of the daily averages of $\mathrm{XCO}_{2}(\mathbf{a}), \mathrm{XCH}_{4}(\mathbf{b})$ and $\mathrm{XCO}(\mathbf{c})$ observed with the EM27/SUN spectrometer. 


\subsection{The Correlation between $\mathrm{XCH}_{4}, \mathrm{XCO}$, and $\mathrm{XCO}_{2}$}

The sources of the $\mathrm{CO}_{2}$ emissions are fossil fuel use and biological respiration. Photosynthesis is the sink of $\mathrm{CO}_{2}$. The main sources of $\mathrm{CH}_{4}$ are biogenic and artificial. The biogenic source comes from landfills and wetlands, oceans and forest, and artificial sources include fossil fuel burning, waste treatment, and geological sources [21]. In the paper of Denman, $\mathrm{CH}_{4}$ produced by gas and oil production, industry, landfills, and waste treatment accounts for $15 \%$ to $40 \%$ of global anthropogenic $\mathrm{CH}_{4}$ emissions. In addition, bacteria decompose organic carbon, converting it to $\mathrm{CO}_{2}$ and $\mathrm{CH}_{4}$. $\mathrm{CO}$ comes from incomplete combustion, the main sources are biomass burning and fossil fuel [22]. Our site is located on the coastline on the south side of the Liantou peninsula. The coastline is northeastsouthwest. It is adjacent to the South China Sea and the north is a sparsely populated hilly area. Due to air-sea exchange, the photosynthesis of algae and the breathing of animals, the oceans are the sources and sinks of $\mathrm{CO}_{2}$ and $\mathrm{CH}_{4}$.

A correlation study was carried out between $\mathrm{XCH}_{4}, \mathrm{XCO}$, and $\mathrm{XCO}_{2}$ for the entire study period. The diurnal variations of $\mathrm{XCH}_{4}, \mathrm{XCO}$, and $\mathrm{XCO}_{2}$ are highly correlated (Figure 8). Fang et al. (2015) suggest that a correlation coefficient value higher than 0.50 indicates a similar source of $\mathrm{CO}_{2}$ and $\mathrm{CH}_{4}$ [23]. The correlations were determined by linear regression of the data shown in Figure 7. Our study also reveals a strong positive correlation observed between $\mathrm{XCO}_{2}$ and $\mathrm{XCH}_{4}$. For the relationship between $\mathrm{XCO}_{2}$ and $\mathrm{XCH}_{4}$, the linear regression line shows a good correlation with the correlation coefficient $R^{2} \geq 0.5$ (except on 2 and 3 October) - especially, the correlation coefficient $R^{2}=0.82$ on 8 October. The strong correlation between $\mathrm{CO}_{2}$ and $\mathrm{CH}_{4}$ indicates that atmospheric $\mathrm{CO}_{2}$ and $\mathrm{CH}_{4}$ are generated from common sources.

$\mathrm{CO}$ is a product of inefficient combustion that has often been used as a tracer of $\mathrm{CO}_{2}$ from combustion [24]. The correlation slope of $\mathrm{XCO}$ to $\mathrm{XCO}_{2}$ provides a characteristic signature of source regions and source type [25]. In the study of Wunch et al. (2009), the slope of the correlations of XCO to $\mathrm{XCO}_{2}$ was $11 \pm 2 \mathrm{ppb} \mathrm{ppm}^{-1}$ in the South Coast Air Basin around Los Angeles [26] Wang wei et al. (2017) calculated the correlation slope of $\mathrm{CO}$ to $\mathrm{CO}_{2}$ at the Hefei site as $5.66 \mathrm{ppb} \mathrm{ppm}^{-1}$ on 25 October 2014 [27]. However, our studies found a weak correlation in the variation of $\mathrm{CO}_{2}$ and $\mathrm{CO}$ (Figure 8b) during the observations. The correlation coefficient $R^{2} \geq 0.5$ was only on 30th September and 3 October; the weak correlation between $\mathrm{CO}_{2}$ and $\mathrm{CO}$ shows that there is a low influence of combustion emissions on $\mathrm{CO}_{2}$. The correlation slopes of $\mathrm{CO}$ to $\mathrm{CO}_{2}$ were $1.94 \mathrm{ppb} \mathrm{ppm}^{-1}$ and $3.69 \mathrm{ppb} \mathrm{ppm}^{-1}$ on 30th September and 3 October, respectively. The correlation coefficient was much smaller on the other days, suggesting that $\mathrm{CO}_{2}$ is dominated by the biosphere. In particular, the overall respiration component from a densely populated urban area may be significant relative to combustion because respiratory $\mathrm{CO}_{2}$ emissions by urban residents are collocated with urban combustion sources. Our studies found a strong correlation in the variation of $\mathrm{CO}_{2}$ and $\mathrm{CH}_{4}$ (Figure 8a) during the observations. The correlation coefficient of 6 days was greater than 0.5 with a maximum of 0.77 . It shows that $\mathrm{CO}_{2}$ and $\mathrm{CH}_{4}$ have the same source.

The HYSPLIT (the Hybrid Single-Particle Lagrangian Integrated Trajectory) model developed by the NOAA (the National Oceanic and Atmospheric Administration), based on the characteristics of the Lagrangian trajectory, can simulate the track of airflow and clearly indicates the source of the flow. It has been applied to studies on weather and climate. The HYSPLIT model was used to analyze the trajectories of air masses [28]. The calculated trajectories are helpful for resolving the evolution of airflow along the transport pathway.

The concentration of trace gases can be modulated not only by local emission but also by long transport from other regions. During the observation period, the diurnal variations of $\mathrm{XCH}_{4}$ and $\mathrm{XCO}_{2}$ were highly correlated. We computed HYSPLIT backward trajectories for the Maoming area. The trajectories used the GDAS model data on a 0.5 degree latitude longitude spatial resolution. The levels of $1 \mathrm{~km}, 5 \mathrm{~km}$, and $10 \mathrm{~km}$ were taken as the initial height. The time interval was $6 \mathrm{~h}$ for output. Figure 9 shows backward air trajectories 
produced by HYSPLIT between 30 September and 8 October 2018. Figure 9 a shows the $72 \mathrm{~h}$ backward movement trajectories on 3 October. The airflows in Figure 8a are mainly affected by long-range transport from India, Yunnan, and Jiangxi Province. Trajectories for $5 \mathrm{~km}$ and $10 \mathrm{~km}$ heights indicate movement of air masses from western India and the Yunnan province of China, whereas the trajectories dram at a height of $1 \mathrm{~km}$ give hint of trace gas transport from the Jiangxi province. Figure $9 \mathrm{~b}$ shows the $72 \mathrm{~h}$ backward movement trajectories on 6 October. Trajectories at $5 \mathrm{~km}$ and $10 \mathrm{~km}$ heights indicate movement of air masses from the Bay of Bengal, whereas the trajectories dram at a height of $1 \mathrm{~km}$ give a hint of trace gas transport from Jiangsu province. Figure $9 \mathrm{c}$ shows the $72 \mathrm{~h}$ backward movement trajectories on 9 October. The trajectories dram at a height of $10 \mathrm{~km}$ gives a hint of trace gas transport from the Arabian Sea, whereas trajectories for $1 \mathrm{~km}$ and $5 \mathrm{~km}$ heights indicate movement of air masses from Myanmar and Jieyang City. From 30 September to 6 October, the upper atmosphere was mainly transported by external sources and during the whole observation period, the lower atmosphere was mainly affected by local sources. This shows that the high correlation between $\mathrm{CO}_{2}$ and $\mathrm{CH}_{4}$ in Figure 8 is due to the transportation from external sources.
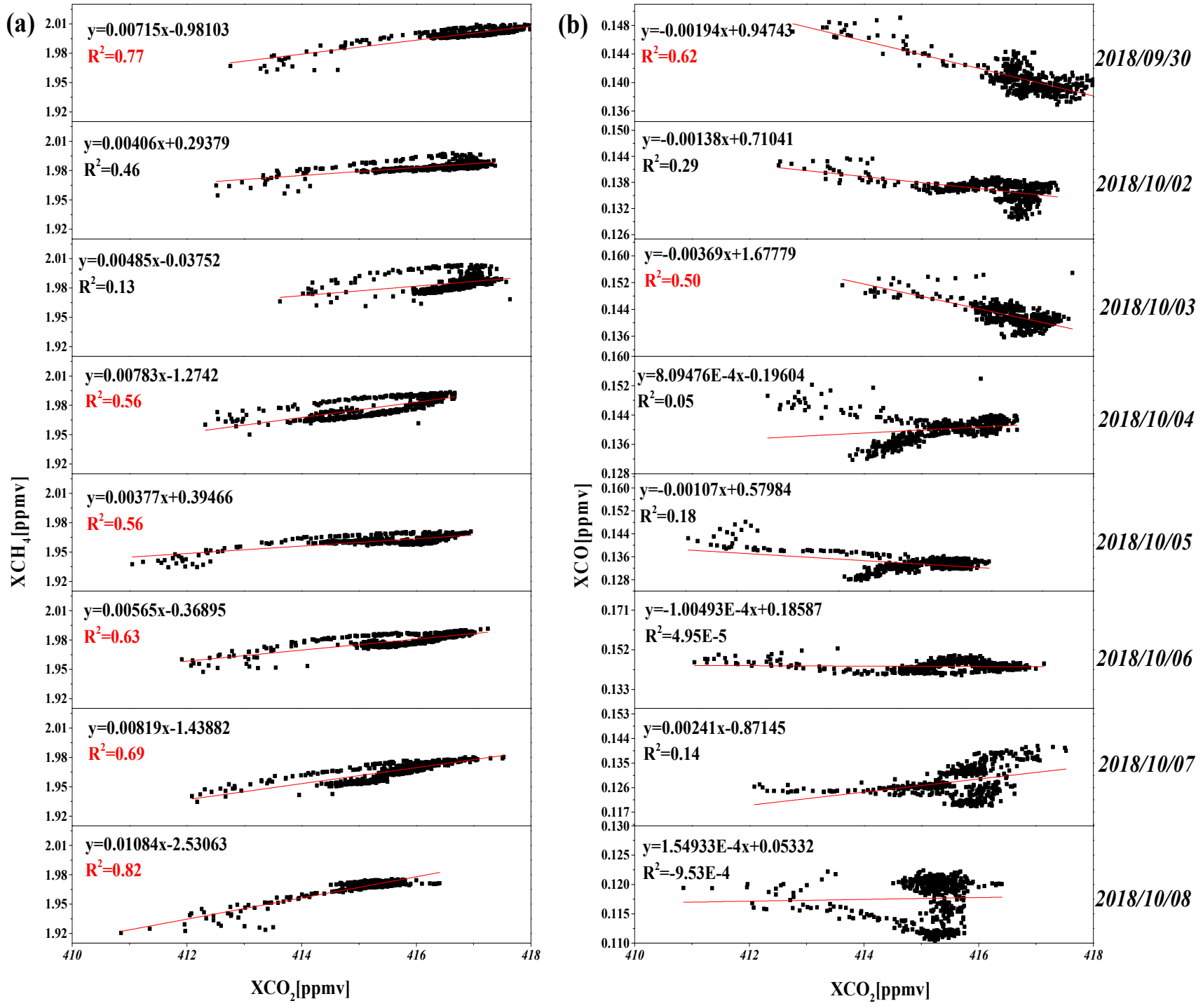

Figure 8. The correlation between $\mathrm{XCH}_{4}$ and $\mathrm{XCO}_{2}(\mathbf{a})$, the correlation between $\mathrm{XCO}$ and $\mathrm{XCO}_{2}(\mathbf{b})$ from 30 September 2018 to 8 October 2018. 

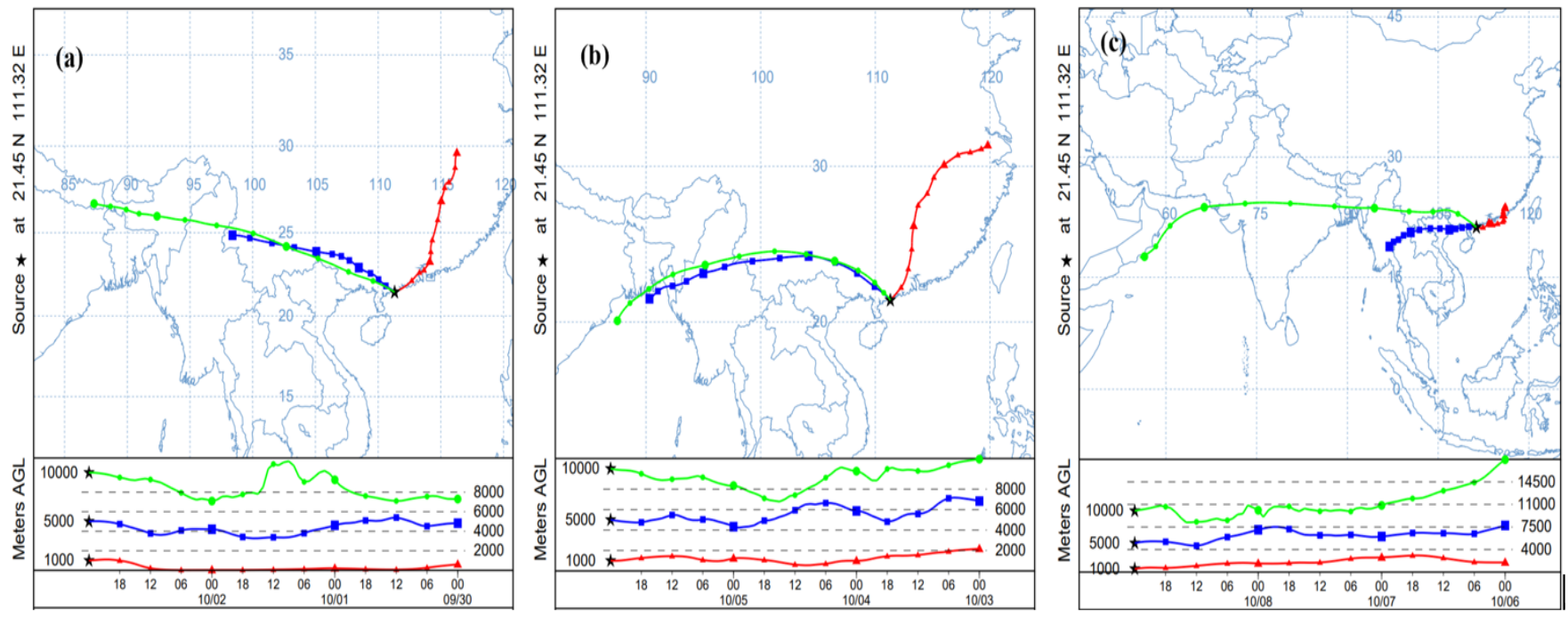

Figure 9. Cluster analysis of $72 \mathrm{~h}$ back trajectories of Maoming from 30 September-8 October, 2018, (a) 30 September-2 October, (b) 2-5 October, (c) 6-9 October.

\section{Conclusions}

In this paper, a solar observatory was deployed at Maoming China to collect nearinfrared solar spectra. We assessed the influence of instrumental line shape degradation on the retrievals of the greenhouse gases. The study concluded that the influence of instrumental line shape degradation can be expressed as the modulation efficiency amplitude influence and the phase error influence. The modulation efficiency amplitude influence is the most important compared to the phase error influence. The means of $\mathrm{XH}_{2} \mathrm{O}, \mathrm{XCH}_{4}$, and XCO with ME values have a positive correlation. The correlation coefficients are 0.9925 , 0.9968 , and 0.9981 respectively. However, the relationship between the mean of $\mathrm{XCO}_{2}$ and $\mathrm{ME}$ is opposite, with a correlation coefficients of 0.986 . For a typical ILS degradation of $1 \%$ in modulation efficiency, the column-averaged dry air mole fraction of $\mathrm{H}_{2} \mathrm{O}, \mathrm{CO}_{2}, \mathrm{CH}_{4}$, and $\mathrm{CO}$ changed by $0.0492,0.1151,0.1042,0.0523 \%$, respectively, while an increase of 0.01 in phase error led to a decrease of $0.697 \%$ on $\mathrm{XH}_{2} \mathrm{O}, 0.689 \%$ on $\mathrm{XCO}_{2}, 0.652 \%$ on $\mathrm{XCH}_{4}$ and $0.737 \%$ on XCO.

The column-averaged dry air mole fraction of $\mathrm{CO}_{2}, \mathrm{CH}_{4}$ and $\mathrm{CO}$ were successfully retrieved from low-resolution ground-based FTS (EM27/SUN) measurements. The daily average of $\mathrm{XCO}_{2}$ ranged from 415.09 to $421.78 \mathrm{ppm}$ during the campaign. $\mathrm{XCH}_{4}$ ranged from 1.96 to $2.02 \mathrm{ppm}$ with a mean of $1.982 \mathrm{ppm}$, showing higher variation than $\mathrm{XCO}_{2}$. The daily average of XCO ranged from 0.118 to $0.157 \mathrm{ppm}$ with a mean of $0.137 \mathrm{ppm}$. At the same time, we analyzed $\mathrm{CH}_{4}$ and $\mathrm{CO}$ correlation with $\mathrm{CO}_{2}$. Our study revealed a strong positive correlation observed between $\mathrm{XCO}_{2}$ and $\mathrm{XCH}_{4}$ with the correlation coefficient $\mathrm{R}^{2} \geq 0.5$. The strong correlation between $\mathrm{CO}_{2}$ and $\mathrm{CH}_{4}$ indicates that atmospheric $\mathrm{CO}_{2}$ and $\mathrm{CH}_{4}$ are generated from common sources. However, there was a weak correlation between $\mathrm{CO}$ and $\mathrm{CO}_{2}$ and the correlation slopes of $\mathrm{CO}$ to $\mathrm{CO}_{2}$ were $1.94 \mathrm{ppb} \mathrm{ppm}^{-1}$ and $3.69 \mathrm{ppb} \mathrm{ppm}^{-1}$ on 30 September and 3 October, respectively; the $\mathrm{CO}_{2}$ is dominated by the biosphere. The results of backward movement trajectories, indicate that the airflows are mainly affected by long-range transport from the Arabian Sea, India, Myanmar, Yunnan and Jiangxi Province. In the near future, more long-term in situ measurements are needed.

Author Contributions: Conceptualization, D.L.; methodology, Z.C. and D.L.; software, D.L. and X.L. (Xingji Lu); validation, D.L. and X.L. (Xiangyuan Liu); formal analysis, D.L.; investigation, D.L.; resources, D.L. and Y.H.; data curation, D.L.; writing-original draft preparation, D.L.; writingreview and editing, D.L.; visualization, D.L.; supervision, Z.C. and Y.H.; project administration, D.L.; funding acquisition, D.L. and X.L. All authors have read and agreed to the published version of the manuscript. 
Funding: This research was funded by the High-level Talents Project of Wanxi University, grant number WGKQ2021007 and the Research project of teachers' domestic visiting in Wanxi University, grant number wxxygnfx2019003.

Institutional Review Board Statement: Not applicable.

Informed Consent Statement: Not applicable.

Data Availability Statement: The data presented in this study are available on request from the corresponding author.

Acknowledgments: The processing environment of PROFFIT programs is provided by the Institute of Meteorology and Climate Research. We thank Qiansi Tu and Frank Hase for support with inversion, and the work was supported by the High-level Talents Project of Wanxi University (Grant No.XDA17010104) and the Research project of teachers' domestic visiting in Wanxi University (Grant No.wxxygnfx2019003).

Conflicts of Interest: The authors declare no conflict of interest.

\section{References}

1. Janardanan, R.; Maksyutov, S.; Oda, T.; Saito, M.; Kaiser, J.W.; Ganshin, A.; Stohl, A.; Matsunaga, T.; Yoshida, Y.; Yokota, T. Comparing GOSAT observations of localized $\mathrm{CO}_{2}$ enhancements by large emitters with inventory based estimates. Geophys. Res. Lett. 2016, 43, 3486-3493. [CrossRef]

2. O'Brien, D.M.; Polonsky, I.N.; Utembe, S.R.; Rayner, P.J. Potential of a geostationary geoCARB mission to estimate surface emissions of $\mathrm{CO}_{2}, \mathrm{CH}_{4}$ and $\mathrm{CO}$ in a polluted urban environment: Case study Shanghai. Atmos. Meas. Tech. 2016, 9, 4633-4654. [CrossRef]

3. Schwandner, F.M.; Gunson, M.R.; Miller, C.E.; Carn, S.A.; Eldering, A.; Krings, T.; Verhulst, K.R.; Schimel, D.S.; Nguyen, H.M.; Crisp, D.; et al. Spaceborne detection of localized carbon dioxide sources. Science 2017, 358, eaam5782. Available online: https:/ / science.sciencemag.org/content/358/6360/eaam5782 (accessed on 5 May 2021). [CrossRef] [PubMed]

4. Broquet, G.; Bréon, F.M.; Renault, E.; Buchwitz, M.; Reuter, M.; Bovensmann, H.; Chevallier, F.; Wu, L.; Ciais, P. The potential of satellite spectro-imagery for monitoring $\mathrm{CO}_{2}$ emissions from large cities. Atmos. Meas. Tech. 2018, 11, 681-708. [CrossRef]

5. Wunch, D.; Toon, G.C.; Blavier, J.F.L.; Washenfelder, R.A.; Notholt, J.; Connor, B.J.; Griffith, D.W.T.; Sherlock, V.; Wennberg, P.O. The total carbon column observing network. Phil. Trans. R.Soc. A 2011, 369, 2087-2112. [CrossRef] [PubMed]

6. Kurylo, M.J. Network for the detection of stratospheric change. Proc. SPIE 1991, 1491, 168-174. [CrossRef]

7. Messerschmidt, J.; Geibel, M.C.; Blumenstock, T.; Chen, H.; Deutscher, N.M.; Engel, A.; Feist, D.G.; Gerbig, C.; Gisi, M.; Hase, F.; et al. Calibration of TCCON column-averaged $\mathrm{CO}_{2}$ : The first aircraft campaign over European TCCON sites. Atmos. Chem. Phys. 2011, 11, 10765-10777. [CrossRef]

8. Gisi, M.; Hase, F.; Dohe, S.; Blumenstock, T.; Simon, A.; Keens, A. $\mathrm{XCO}_{2}$-measurements with a tabletop FTS using solar absorption spectroscopy. Atmos. Meas. Tech. 2012, 5, 2969-2980. [CrossRef]

9. Hase, F.; Frey, M.; Blumenstock, T.; Groß, J.; Kiel, M.; Kohlhepp, R.; Mengistu Tsidu, G.; Schäfer, K.; Sha, M.K.; Orphal, J. Application of portable FTIR spectrometers for detecting greenhouse gas emissions of the major city Berlin. Atmos. Meas. Tech. 2015, 8, 3059-3068. Available online: https:/ /amt.copernicus.org/articles/8/3059/2015/amt-8-3059-2015 (accessed on 5 May 2021). [CrossRef]

10. Frey, M.; Hase, F.; Blumenstock, T.; Groß, J.; Kiel, M.; Tsidu, G.M.; Schäfer, K.; Sha, M.K.; Orphal, J. Use of portable FTIR spectrometers for detecting greenhouse gas emissions of the megacity Berlin-Part 1: Instrumental line shape characterisation and calibration of a quintuple of spectrometers. Atmos. Meas. Tech. 2015, 8, 3047-3057. [CrossRef]

11. Frey, M. Characterisation and Application of Portable Solar Absorption Spectrometers for the Detection of Greenhouse Gas Emissions from Regional Anthropogenic Sources. Ph.D. Thesis, Karlsruhe Institute for Technolgy (KIT), Karlsruhe, Germany, 2018.

12. Klappenbach, F.; Bertleff, M.; Kostinek, J.; Hase, F.; Blumenstock, T.; Agusti-Panareda, A.; Razinger, M.; Butz, A. Accurate mobile remote sensing of $\mathrm{XCO}_{2}$ and $\mathrm{XCH}_{4}$ latitudinal transects from aboard a research vessel. Atmos. Meas. Tech. 2015, 8, 5023-5038. [CrossRef]

13. Norton, R.H.; Beer, R. New apodizing functions for Fourier spectrometry. J. Opt. Soc. Am. 1976, 67, 419. Available online: https: //www.researchgate.net/publication/23822078_New_apodizing_functions_for_Fourier_spectrometry (accessed on 5 May 2021). [CrossRef]

14. Davis, S.P.; Abrams, M.C.; Brault, J.W. Fourier Transform Spectrometry; Academic Press: Cambridge, MA, USA, 2001; ISBN 0-12-042510-6.

15. Hase, F.; Blumenstock, T.; Paton-Walsh, C. Analysis of the instrumental line shape of high resolution Fourier transform IR spectrometers with gas cell measurements and new retrieval software. Appl. Opt. 1999, 38, 3417-3422. [CrossRef] [PubMed]

16. Kiel, M.; Wunch, D.; Wennberg, P.O.; Toon, G.C.; Hase, F.; Blumenstock, T. Improved retrieval of gas abundances from nearinfrared solar FTIR spectra measured at the Karlsruhe TCCON station. Atmos. Meas. Tech. 2016, 9, 669-682. [CrossRef] 
17. Frey, M.; Sha, M.K.; Hase, F.; Kiel, M.; Blumenstock, T.; Harig, R.; Surawicz, G.; Deutscher, N.M.; Shiomi, K.; Franklin, J.; et al. Building the Collaborative Carbon Column Observing Network (COCCON): Long-term stability and ensemble performance of the EM27/SUN Fourier transform spectrometer. Atmos. Meas. Tech. 2019, 12, 1513-1530. [CrossRef]

18. Rodgers, C.D.; Connor, B.J. Intercomparison of remote sounding instruments. J. Geophys. Res. Atmos. 2003, 108. [CrossRef]

19. Hedelius, J.K.; Viatte, C.; Wunch, D.; Roehl, C.M.; Toon, G.C.; Chen, J.; Jones, T.; Wofsy, S.C.; Franklin, J.E.; Parker, H.; et al. Assessment of errors and biases in retrievals of $\mathrm{XCO}_{2}, \mathrm{XCH}_{4}, \mathrm{XCO}$, and $\mathrm{XN}_{2} \mathrm{O}$ from a $0.5 \mathrm{~cm}^{-1}$ resolution solar viewing spectrometer. Atmos. Meas. Tech. 2016, 9, 3527-3546. [CrossRef]

20. Macdonald, J.; Fowler, D.; Hargreaves, K.; Skiba, U.; Leith, I.; Murray, M. Methane emission rates from a northern wetland; response to temperature, water table and transport. Atmos. Environ. 1998, 32, 3219-3227. [CrossRef]

21. Denman, K.; Brasseur, G.P.; Chidthaisong, A.; Ciais, P.; Cox, P.M.; Dickinson, R.; Haugustaine, D.; Heinze, C.; Holland, E.A.; Jacob, D.; et al. Couplings between changes in the climate system and biogeochemistry. In Climate Change 2007: The Physical Science Basis. Contribution of Working Group I to the Fourth Assessment Report of the Intergovernmental Panel on Climate Change; Solomon, S., Qin, D., Manning, M., Chen, Z., Marquis, M., Averyt, K.B., Tignor, M., Miller, H.L., Eds.; Cambridge University Press: Cambridge, UK, 2007; pp. 499-587.

22. Montzka, S.; Fraser, P.J.; Butler, J.H.; Cunnold, D.M.; Daniel, J.S.; Derwent, R.G.; Lal, S.; McCulloch, A.; Oram, D.E.; Reeves, C.E.; et al. Controlled substances and other source gases, Chapter 1 of the Scientific Assessment of Ozone Depletion: 2002. In Scientific Assessment of Ozone Depletion: 2002; World Meteorological Organization: Geneva, Switzerland, 2003; Volume 47, pp. 1.1-1.83.

23. Fang, S.X.; Tans, P.P.; Steinbacher, M.; Zhou, L.X.; Luan, T. Comparison of the regional $\mathrm{CO}_{2}$ mole fraction filtering approaches at a WMO/GAW regional station in China. Atmos. Meas. Tech. 2015, 8, 5301-5313. [CrossRef]

24. Turnbull, J.C.; Miller, J.B.; Lehman, S.J.; Tans, P.P.; Sparks, R.J.; Southon, J. Comparison of ${ }^{14} \mathrm{CO}_{2}$, CO, and SF6 as tracers for recently added fossil fuel $\mathrm{CO}_{2}$ in the atmosphere and implications for biological $\mathrm{CO}_{2}$ exchange. Geophys. Res. Lett. 2006, 33, L01817. [CrossRef]

25. Wang, Y.; Munger, J.W.; Xu, S.; McElroy, M.B.; Hao, J.; Nielsen, C.P.; Ma, H. $\mathrm{CO}_{2}$ and its correlation with $\mathrm{CO}$ at a rural site near Beijing: Implications for combustion efficiency in China. Atmos. Chem. Phys. 2010, 10, 8881-8897. [CrossRef]

26. Wunch, D.; Wennberg, P.O.; Toon, G.C.; Keppel-Aleks, G.; Yavin, Y.G. Emissions of greenhouse gases from a North American megacity. Geophys. Res. Lett. 2009, 36, L15810. [CrossRef]

27. Wang, W.; Tian, Y.; Liu, C.; Sun, Y.; Liu, W.; Xie, P.; Liu, J.; Xu, J.; Morino, I.; Voltaire, A.; et al. Investigating the performance of a greenhouse gas observatory in Hefei, China. Atmos. Meas. Tech. 2017, 10, 2627-2643. [CrossRef]

28. Draxler, R.R.; Hess, G.D. An overview of the HYSPLIT 4 modeling system for trajectories, dispersion, and deposition. Aust. Met. Mag. 1998, 47, 295-308. 